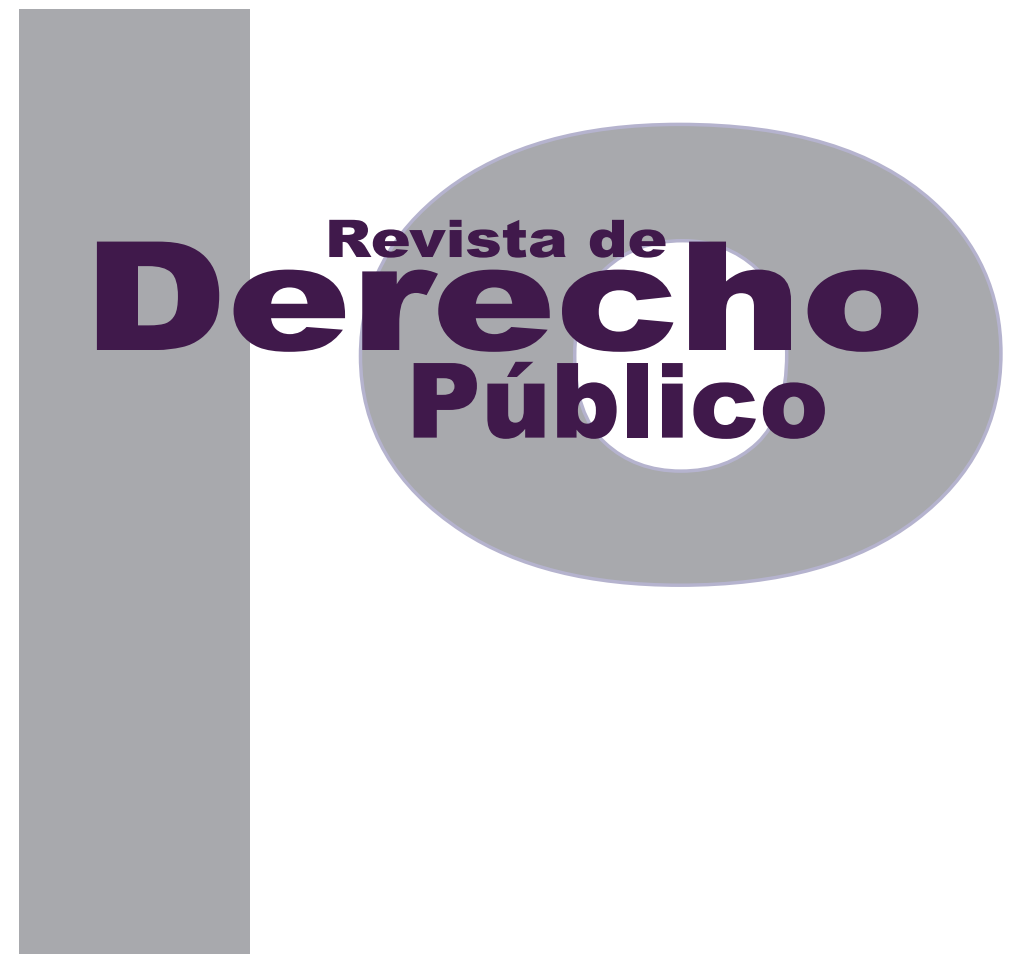

\title{
INCONSTITUCIONALIDAD DEL ARTÍCULO 2 DEL DECRETO 0934 DE 2013 QUE IMPIDE LA PROHIBICIÓN TERRITORIAL DE LA MINERÍA
}

\author{
RAisSA MORELLA CARRILlO VilLAMIZAR
}

DOI: http://dx.doi.org/10.15425/redepub.33.2014.12

Universidad de los Andes

Facultad de Derecho

Revista de Derecho Público N. ${ }^{\circ} 33$

Julio - Diciembre de 2014. ISSN 1909-7778 


\title{
Inconstitucionalidad del artículo 2 del Decreto 0934 de 2013 que impide la prohibición territorial de la minería
}

\section{Resumen}

En este ensayo se analiza la prohibición contenida en el Decreto 0934 de 2013 del Ministerio de Minas y Energía, dirigida a entidades territoriales relevando de su competencia la regulación de la actividad minera, de manera directa o indirecta. Se limita a estudiar las afectaciones que derivan sobre el principio de precaución, el principio democrático, el ejercicio de la función pública y la formulación de políticas públicas de prevención bajo el estudio del patrón de autoproclamación no minera de concejos municipales en el territorio nacional. Esto ilustra (i) el desacuerdo entre el modelo de desarrollo escogido a nivel territorial y el establecido a nivel nacional que da prelación a la minería a pesar de las manifestaciones sociales en su contra, en razón del deterioro que ocasiona sobre el medio ambiente y la salud; (ii) cómo esta contradicción política se ve reflejada en la restricción de competencias de las autoridades territoriales por parte del gobierno central, desatando fallas en la estructura del Estado y deficiencias en el desempeño de principios centrales del derecho administrativo.

Palabras clave: principio de precaución, principio democrático, principio de descentralización, principio de rigor subsidiario, derecho ambiental, Constitución ecológica, minería, política minera en Colombia.

\section{Constitutional analysis of article 2 of Decree 0934 of 2013 that inhibits the territorial mining ban}

\begin{abstract}
This essay analyzes the ban established by the Decree 0934 of 2013 issued by the Ministry of Mines and Energy, relieving territorial authorities from its jurisdiction to regulate mining activities directly or indirectly. The scope of this study is limited to the restrictions arising on precautionary principle, the democratic principle, the exercise of public functions and public policy prevention based on the case of self-proclaimed non-mining districts in Colombia. This illustrates a disagreement over the development model chosen at the territorial and national level. The last gives priority to mining activity which injuries the environment and health, despite local social rejection. This text shows how this policy contradiction is reflected by the restriction of local authorities' jurisdiction by the central government, triggering failures in the structure of the state and substantial deficiencies of performance of administrative law's principles.

Keywords: precautionary principle, democratic principle, decentralization, subsidiarity principle, mining policy in Colombia.

\section{Inconstitucionalidade do artigo 2 do Decreto 0934 de 2013 que impede a proibição territorial da mineração}

\section{Resumo}

Neste ensaio é analisada a proibição contida no Decreto 0934 de 2013 do Ministério de Minas e Energia, dirigida a entidades territoriais relevando de sua competência a regulação da atividade mineira, de maneira direta ou indireta. Limitase a estudar as afetações que derivam sobre o princípio de precaução, o princípio democrático, o exercício da função pública e a formulação de políticas públicas de prevenção sob o estudo do padrão de autoproclamação não mineira de concelhos municipais no território nacional. Isto ilustra (i) o desacordo entre o modelo de desenvolvimento escolhido a nível territorial e o estabelecido a nível nacional que dá prelação à mineração apesar das manifestações sociais contra, em razão do deterioro que ocasiona sobre o meio ambiente e a saúde; (ii) como esta contradição política se vê refletida na restrição de competências das autoridades territoriais por parte do governo central, desatando falhas na estrutura do Estado e deficiências no desempenho de princípios centrais do direito administrativo.

Palavras-chave: princípio de precaução, princípio democrático, princípio de descentralização, princípio de rigor subsidiário, direito ambiental, Constituição ecológica, mineração, política mineira na Colômbia. 


\title{
Inconstitucionalidad del artículo 2 del decreto 0934 de 2013 que impide la prohibición territorial de la minería*
}

\author{
Raissa Morella Carrillo Villamizar**
}

\begin{abstract}
SUMARIO
Introducción - I. CONTEXTUALIZACIÓN: DIVERGENCIA ENTRE EL NIVEL NACIONAL Y EL TERRITORIAL SOBRE LA ACEPTACIÓN DE LA MINERÍA - A. Contexto de la política minera colombiana - B. Caso de estudio de municipios no mineros en Colombia: origen social - II. LIMITACIÓN DEL PRINCIPIO DE PRECAUCIÓN - A. Concepto del principio de precaución en el sistema jurídico colombiano - B. Casos de municipios emblemáticos del principio de precaución - C. La vulneración del principio de precaución - III. LIMITACIÓN DE PRINCIPIOS CONSTITUCIONALES DE DISEÑO INSTITUCIONAL - A. La participación democrática - B. Función pública - C. Política pública - IV. CONCLUSIONES - Referencias.
\end{abstract}

Cómo citar este artículo: Carrillo Villamizar, R. M. (Diciembre, 2014). Inconstitucionalidad del artículo 2 del Decreto 0934 de 2013 que impide la prohibición territorial de la minería. Revista de Derecho Público, 33. Universidad de los Andes (Colombia).

** Abogada de la Universidad de los Andes con Opción en Ciencia Política. Este documento es una versión corregida de la tesis de grado presentada ante la Facultad de Derecho el 18 de noviembre de 2013, dirigida por la profesora Federica Salazar. 


\section{Introducción}

El objeto de estudio de este texto es la afectación del principio de precaución, el principio democrático, el ejercicio de la función pública y la formulación de políticas públicas de prevención causada por la prohibición contenida en el artículo 2 del Decreto 934 de 2013, expedido por el Ministerio de Minas y Energía (en adelante MME), consistente en sustraer la competencia de entidades territoriales de cualquier tipo de disposición, directa e indirecta, sobre la minería. En particular, el artículo 2 dispone que:

Dado el carácter de utilidad pública e interés social de la minería, a través del Ordenamiento Territorial no es posible hacer directa ni indirectamente el Ordenamiento Minero, razón por la cual los planes de ordenamiento territorial, planes básicos de ordenamiento territorial o esquemas de ordenamiento territorial de los municipios y distritos, no podrán incluir disposiciones que impliquen un ordenamiento de la actividad minera en el ámbito de su jurisdicción, salvo previa aprobación de las autoridades nacionales.

Parágrafo 1.- En desarrollo de la anterior prohibición, los Concejos Municipales y las Asambleas Departamentales no podrán establecer zonas del territorio que queden permanentemente o transitoriamente excluidas de la minería mediante acuerdos municipales $u$ ordenanzas departamentales respectivamente, por exceder el ámbito de sus competencias.

Parágrafo 2.- Las prohibiciones que se establezcan en los mencionados instrumentos de ordenamiento del territorio en violación de la ley, no podrán ser oponibles, aplicadas o exigidas a las actividades mineras, por ninguna autoridad.

El estudio propuesto de la prohibición contenida en la norma citada se concentra en señalar sus efectos restrictivos en relación con el principio de precaución, el principio democrático, al ejercicio de la función pública y la formulación de políticas públicas de prevención en materia minera, los cuales han sido el fundamento jurídico de las decisiones tomadas por entidades territoriales, en particular por los concejos municipales, quienes amparados por la autonomía territorial y buscando una regulación restrictiva prohíben y excluyen la actividad minera de la economía de sus regiones como un medio de control de las afectaciones que esta produce. Es preciso aclarar de antemano que, si bien el principio de precaución no es nombrado de manera expresa en los fundamentos de las decisiones territoriales, es pertinente su análisis pues, en todo caso, estas decisiones se originan en preocupaciones que pueden ser enmarcadas en él como se explicará en el desarrollo de este texto.

Este documento se divide en tres apartados. Inicialmente se expone el contexto colombiano actual referente a la tendencia municipal de declararse territorio no minero -poniendo en evidencia que las decisiones tomadas por entidades territoriales responden a reivindicaciones sociales basadas en preocupaciones de índole ambiental y de salud-versus la política minera nacional, lo que permitirá probar la oposición entre el interés local y el nacional con relación 
al impulso del sector minero energético, originada en la diferencia en la elección del modelo de desarrollo a implementar.

En seguida, gracias a la explicación previa del origen social de las decisiones territoriales en contra de la minería y la exposición sobre qué es el principio de precaución, se justifica por qué los acuerdos municipales que la excluyen de ciertos territorios pueden ser considerados una manifestación de este. Finalmente, se examina la afectación del principio de precaución a la luz de la norma estudiada: el artículo 2 del Decreto 394 de 2013.

Posteriormente, se exponen las acotaciones originadas por la norma en análisis sobre el principio democrático, el ejercicio de la función pública y la formulación de políticas públicas de prevención, respectivamente, haciendo también referencia a la falta de competencia del MME para restringir las atribuciones de los entes territoriales, como lo hace mediante la norma analizada.

De lo anterior se concluye que la restricción de competencias de las autoridades territoriales por parte del gobierno central origina fallas en la estructura del Estado y provoca desequilibrio en elementos sustanciales del derecho administrativo.
I. CONTEXTUALIZACIÓN: DIVERGENCIA ENTRE EL NIVEL NACIONAL Y EL TERRITORIAL SOBRE LA ACEPTACIÓN DE LA MINERÍA

\section{A. Contexto de la política minera} colombiana

América Latina es reconocida por su gran biodiversidad. Colombia, por su parte, alberga el $10 \%$ de la biodiversidad mundial, a pesar de representar únicamente el $0.7 \%$ de la superficie continental mundial (Ministerio del Medio Ambiente, Departamento Nacional de Planeación e Instituto Alexander von Humboldt, s. f.). En este contexto, se adoptó el Convenio sobre Diversidad Biológica en Colombia, mediante las leyes 162 y 165 de 1994, revisadas respectivamente por la sentencia C-519 de 1994. En este mismo ánimo de conservación, Colombia ha suscrito 68 tratados internacionales relacionados directamente con la protección del medio ambiente (Departamento Nacional de Planeación, s. f.). No obstante, esto contrasta con el notorio desarrollo del sector minero desde hace un par de décadas.

El desarrollo del sector minero colombiano se remonta a la crisis económica de los años ochenta. Así como otros países en vía de desarrollo, Colombia aceptó un modelo de Estado neoliberal que respondía a las exigencias del sistema internacional y de órganos de financiamiento multilateral, facilitando el acceso a los recursos naturales y su explotación por parte del capital privado (Reyes Beltrán y León, 2012). 
En este contexto, se impulsaron medidas favorables a las actividades extractivas como parte de un proyecto político que alude al desarrollo que estas pueden generar gracias a la ventaja comparativa que le representan en el comercio internacional. Por ello, la minería adquirió un papel central en la economía de la región; Indepaz (2012) reporta que “(e)ntre 1990 y 1997, las inversiones en exploración minera crecieron en un $90 \%$ a nivel mundial, en América Latina lo hicieron en $400 \%$, totalizando una inversión acumulada por US\$17.300 millones".

El boom del sector minero acentúa la tensión entre la obligación de proteger el medio ambiente y el desarrollo de la actividad extractiva, ya que a pesar del crecimiento que refleja en los indicadores económicos también reporta externalidades negativas tanto económicas como ambientales y sociales. Idarraga Franco (2012) enuncia someramente algunas de estas críticas desde distintas perspectivas:

desde el ecologismo se cuestionan sus impactos socio ambientales, la distribución ecológica desigual y la deuda ambiental alrededor del control y uso de los recursos naturales, que emerge de los conflictos que genera. En segundo lugar, desde la economía se llama la atención sobre el peligro latente de la "enfermedad holandesa", producto del crecimiento súbito en los ingresos por exportaciones, que generan perturbaciones macroeconómicas causantes de aumentos en el gasto público, inflación, caída de la tasa de cambio real y "desindustrialización", y desde la economía política se hace referencia a la acumulación por desposesión, que explica cómo a través de la privatización y la violencia se resuelven los problemas de sobreacumulación. Finalmente desde los conflictos culturales distributivos se afirma que la modernidad dominante, que justifica la idea desarrollista de la necesidad minera, genera problemas de distribución cultural -negación de la diferencia cultural- e impone una visión del mundo, una norma, que se universaliza por un efecto de hegemonía y no en virtud de su contenido de verdad (pp. 97-98).

A pesar de las desventajas ocasionadas por actividades extractivas a gran escala, el modelo extractivo en Colombia predomina desde hace varias décadas. En particular, se acentuó durante el gobierno de Uribe, en el cual la superficie de hectáreas con título minero pasó de 1,13 millones a 8,53 millones (Osorio, 2010).

En seguida, el gobierno de Juan Manuel Santos definió la prioridad de formular y adoptar políticas dirigidas al aprovechamiento sostenible de los recursos mineros y energéticos para contribuir al desarrollo económico y social del país, como lo sugiere en el Plan Nacional de Desarrollo "Prosperidad para Todos". El PIB minero en Colombia representó el 2,01\% del PIB total del primer trimestre de 2013, tuvo una variación negativa al caer $14,05 \%$ con respecto al primer trimestre de 2012, pasando de 2,80 a 2,40 billones de pesos, pese a que la participación del sector minas en el PIB total trimestral en los últimos años se ha mantenido por encima del 2,00\% y el sector de minas e hidrocarburos por encima del 7,00\%, lo cual se mantuvo para el primer trimestre de 2013 (Dirección de Minería Empresarial, 2013).

Adicionalmente, como parte de esta agenda se realizó una reforma de las carteras de Medio 
Ambiente y de Minas (2010-2011). Esto aseguraría el buen desarrollo del sector, la colaboración entre entidades ambientales y mineras, y la seguridad jurídica para los inversionistas. De ella resultó una estructura institucional más compleja, integrada por el Ministerio de Minas y Energía, la Agencia Nacional de Minería (AnM) ${ }^{1}$ y la Unidad de Planeación Minero Energética (UPME) $)^{2}$, entes que deben colaborar con el Ministerio de Ambiente y Desarrollo Sostenible (MADS) y sus entidades desconcentradas (Corporaciones Autónomas Regionales, Corporaciones de Desarrollo Social, Sistema Integrado Nacional Ambiental y la Agencia Nacional de Licencias Ambientales). Así mismo, vale la pena resaltar la creación del sistema de información unificada e integrada: el Sistema de Información Minero Energético Colombiano (SIMEC).

\section{B. Caso de estudio de municipios no mineros en Colombia: origen social}

A pesar de la promoción nacional de la minería, en este contexto, la prohibición minera territorial se ha propagado coordinando la política pública ambiental y de desarrollo social desde la base social. Las comunidades han tomado partido en contra de la minería teniendo en cuenta que, entre otros, como lo sugiere García Parra (2012), en los proyectos mineros:

1 Creada por el Decreto 4134 de 2011 expedido por el MME, como entidad adscrita al MME según el Decreto 0381 de 2012.

2 Unidad Administrativa Especial creada por Decreto 2119 del 29 de diciembre de 1992, adscrita al MME, cuyas funciones están establecidas por la Ley 143 del 11 de julio de 1994. no solo se contamina el agua con cianuro y metales pesados, sino que se destruye su ciclo, la capacidad de acumulación, todo el proceso de infiltración de aguas subterráneas y la escorrentía, dado que se acaba con los bosques y se plastifican miles de hectáreas. Los aspectos más graves de la degradación ambiental de este tipo de emprendimientos son: pérdida de biodiversidad y coberturas vegetales (destrucción de los nichos ecológicos), contaminación de suelos, agua y aire y daños de calidad y disponibilidad del agua (p. 453).

El Centro de Investigación y Educación Popular (CINEP, 2012) descubrió que entre enero de 2001 y diciembre de 2011 se llevaron a cabo en Colombia 274 acciones colectivas sociales asociadas con la extracción de petróleo, carbón y oro, y que la protesta social en contra de la extracción de minerales aumentó de manera constante desde 2005.

La tendencia del descontento, en aumento, explica las dimensiones de las protestas que han tenido lugar, por ejemplo, la participación de 40 000 personas en la marcha realizada en Bucaramanga en defensa del páramo de Santurbán, en febrero de 2011, amenazado por el proyecto Angostura de la minera Greystar; dos multitudinarias marchas en contra del proyecto La Colosa, en Tolima, en las que el gobernador estimó la participación de 5000 personas (Redacción Tolima, 2013), y las continuas manifestaciones en la provincia de García Rovira (Santander) en contra del proyecto carbonífero en el páramo El Almorzadero (Roa Avendaño, 2013).

Así mismo, la oposición acérrima en contra de la minería ha permitido frenar grandes proyectos 
de extracción entre los cuales están el proyecto en el páramo El Almorzadero, en el páramo de Santurbán y el proyecto Mazamorras Gold en Nariño. En el primero, a pesar de las continuas manifestaciones sociales durante el proceso de socialización rechazando el proyecto, solo la coalición política de gobernantes de Santander y Norte de Santander que logró la declaratoria de parte del páramo de Santurbán como Parque Natural Regional pudo frenar el proceso de licenciamiento por parte del MADS. La Resolución 1510 de mayo del 2011 negó la solicitud de licencia ambiental para la explotación de oro y plata en los municipios de California y Vetas por encontrarse en zonas protegidas por el Acuerdo Regional (Flórez, 2013).

En el segundo, las protestas y la tensión llegaron a ser tan altas que provocaron violencia entre los trabajadores de la mina y los miembros de la comunidad. La confrontación fue tan grande que quemaron algunos campamentos mineros en octubre de 2011 y se hizo necesaria la presencia del Escuadrón Móvil Antidisturbios (ESMAD) de la Policía Nacional, lo que desató aún más violencia y ocasionó la muerte de uno de Ios líderes. Como resultado, la Gran Colombia Gold decidió suspender las actividades mineras y la venta del proyecto (ABColombia, 2012).

No obstante, la utilización de instrumentos territoriales en contra de la minería es una acción promovida por primera vez en Colombia por el Cinturón Occidental Ambiental "Suroeste de Antioquia: territorio sagrado para la vida" (COA), movimiento creado en el 2011 y que reúne los municipios de Támesis, Jericó, Pueblo Rico,
Valparaíso, La Pintada, Venecia y Jardín, entre otros. Allí, mediante la expedición de acuerdos por los concejos municipales de la subregión, impulsados por el COA, la Organización Indígena de Antioquia (OIA) y la ong Corporación Conciudadanía, lograron coordinar esfuerzos y políticas para ordenar el uso del suelo como mecanismo de defensa (Conciudadanía, 2013). Municipios como Líbano y Piedras en el Tolima, y Cerrito en Santander, entre otros, siguieron el ejemplo, obstaculizando grandes inversiones y proyectos como La Colosa, de Anglogold Ashanti y Angostura en los páramos de Santurbán y El Almorzadero (Sandoval, 2013). Igualmente, mediante el Decreto 364 de 2013 se realizó una modificación extraordinaria al Plan de Ordenamiento Territorial de Bogotá D. C., en el que se incluyó la prohibición de nuevas actividades extractivas y se establecieron escenarios de transición de áreas que contaban con título, permiso u otra autorización minera vigente y con licencia ambiental o plan de manejo ambiental y zonas de transición contiguas protegidas de riesgos derivados de dicha actividad extractiva.

Estas proclamaciones en contra de la minería ejemplifican el desacuerdo sobre la concepción de desarrollo a nivel local y nacional. Las disposiciones en contra de la minería consagradas en los acuerdos de los concejos municipales contrastan abiertamente con el modelo extractivo del Plan Nacional de Desarrollo, que proyecta el sector como predominante en la economía nacional hacia el 2019.

Este fenómeno se ha concentrado en departamentos donde confluye la ubicación de reservas 
importantes de oro, plata, carbón y níquel -principalmente-, el licenciamiento para los grandes proyectos de extracción y las luchas sociales. Estas últimas, bajo la forma de protestas y movilizaciones culturales y sociales, expresan la disconformidad de las comunidades con (i) el licenciamiento de la mayor parte del territorio, (ii) con el conflicto que dicho licenciamiento genera en zonas protegidas o excluidas por motivos culturales, sociales y ambientales y (iii) con los desplazamientos, riesgos sobre la salud y el medio ambiente que ocasiona, incluso acentuando enfrentamientos armados (Fierro, 2012).

\section{LIMITACIÓN DEL PRINCIPIO DE PRECAUCIÓN}

Teniendo en cuenta la relación sobre el origen social de las decisiones territoriales en contra de la minería, expuesta en la sección anterior, aquí se explica por qué los acuerdos que excluyen la minería de ciertos territorios pueden ser considerados como una manifestación del principio de precaución y cómo este se afecta por la prohibición de la norma estudiada.

\section{A. CONCEPTO DEL PRINCIPIO DE PRECAUCIÓN EN EL SISTEMA JURÍDICO COLOMBIANO}

Para entender por qué los casos de territorios proclamados no mineros son una manifestación del principio de precaución (PP) debemos explicar preliminarmente en qué consiste. El pp es la obligación a cargo del Estado y los particulares de tomar medidas para proteger y mitigar daños en el ambiente y la salud que sean resultado de las externalidades de actividades humanas y de algunos productos, cuando existe alguna evidencia científica que indica que en alguna medida son nocivas para la salud y el medio ambiente. Esto quiere decir que no se requiere certeza absoluta sobre el daño y el grado de este, que pueda ocasionar la actividad motivo de debate. Contrariamente, el principio de prevención se refiere a la obligación del Estado de evitar daños ambientales cuando ya existe certeza de estos por parte de la actividad (Soto, 1996-1997). Ambos distan en que la obligación de actuar emana de un grado de certeza sobre el daño menos intenso en el caso del principio de precaución, y sobre un daño mayor en el principio de prevención. Santana (2013, p. 20) sintetiza las diferencias entre uno y otro en la siguiente tabla:

\begin{tabular}{|c|c|c|}
\hline $\begin{array}{c}\text { Caracte- } \\
\text { rística }\end{array}$ & Prevención & Precaución \\
\hline $\begin{array}{l}\text { Tempo- } \\
\text { ralidad }\end{array}$ & $\begin{array}{l}\text { Implica conocer } \\
\text { anticipadamente las } \\
\text { consecuencias que } \\
\text { una determinada } \\
\text { actividad puede } \\
\text { tener para el medio } \\
\text { ambiente, conside- } \\
\text { rada en una escala } \\
\text { de tiempo que co- } \\
\text { rresponde al media- } \\
\text { no y largo plazo. }\end{array}$ & $\begin{array}{l}\text { Se refiere esencialmen- } \\
\text { te a los riesgos estima- } \\
\text { dos en una escala tem- } \\
\text { poral correspondiente } \\
\text { a la larga duración. }\end{array}$ \\
\hline $\begin{array}{c}\text { Certeza } \\
\text { científica }\end{array}$ & $\begin{array}{l}\text { Su fundamento es } \\
\text { el conocimiento an- } \\
\text { ticipado del daño y } \\
\text { de las medidas que } \\
\text { podrían adoptarse } \\
\text { para evitarlo. }\end{array}$ & $\begin{array}{l}\text { Se basa en la falta de } \\
\text { certeza científica que } \\
\text { en algunos casos puede } \\
\text { ser absuelta y, en otros, } \\
\text { dependiendo del meca- } \\
\text { nismo que lo consagre, } \\
\text { puede ser solamente } \\
\text { cuestionable. }\end{array}$ \\
\hline $\begin{array}{l}\text { Nivel de } \\
\text { riesgo }\end{array}$ & $\begin{array}{l}\text { El peligro al medio } \\
\text { ambiente no nece- } \\
\text { sariamente tiene } \\
\text { que ser significativo, } \\
\text { basta con que haya } \\
\text { afectación negativa. }\end{array}$ & $\begin{array}{l}\text { En la mayoría de los } \\
\text { casos implica que los } \\
\text { riesgos son graves e } \\
\text { irreversibles o, por lo } \\
\text { menos, significativos. }\end{array}$ \\
\hline
\end{tabular}


Pese a que el principio de precaución no está contemplado en la Constitución Política (cP), esta contiene una serie de elementos que hacen referencia a la tendencia ambiental vanguardista que se le ha atribuido en la doctrina. La Carta Magna, a pesar de no disponer expresamente el PP, incorpora principios fundamentales asociados a este, y mandatos ecológicos y de protección del medio ambiente (Uprimmy Yepes y Orduz Salinas, 2012)3. Así mismo, el bloque de constitucionalidad ha sido la vía de entrada del principio consagrado de manera formal a causa de la internacionalización de las relaciones ecológicas que caracteriza el final del siglo XX (Corte Constitucional. Sentencia C-671 de 2001). En efecto, el concepto colombiano del pP está permeado por la influencia del derecho internacional ambiental, que hace parte del ordenamiento jurídico a través del bloque de constitucionalidad, y le atribuye rango constitucional y carácter vinculante. ${ }^{4}$ Sobresale la formulación

3 A manera de ejemplo podemos referirnos al preámbulo que hace mención a la protección de la vida y a los artículos: 8 (obligación de proteger las riquezas culturales y naturales de la Nación), 58 (función ecológica de la propiedad), 79 (derecho a un ambiente sano y participación en las decisiones ambientales), 80 (planificación del manejo y aprovechamiento de los recursos naturales), 215 (estado de emergencia por desastre ambiental), 300-2 (asambleas departamentales y medio ambiente), 313-9 (concejos municipales y patrimonio ecológico), 317 y 294 (contribución de valorización para la conservación del ambiente y los recursos naturales), 333 (limitaciones a la libertad económica por razones del medio ambiente), 334 (intervención estatal para la preservación de los recursos naturales y un ambiente sano), 339 (política ambiental en el plan nacional de desarrollo), 340 (representación de los sectores ecológicos en el Consejo Nacional de Planeación), entre otras disposiciones enlistadas en la sentencia C-595 de 2010.

$4 \quad$ Art. 93 CP. Ver, por ejemplo, la Convención Marco de las Naciones Unidas sobre el Cambio Climático aprobada por la Ley 164 de 1994 y la Declaración de Río de Janeiro de junio de 1992 sobre Medio Ambiente y Desarrollo. El principio ingresó al ordenamiento jurídico colombiano a través del bloque de constitucionalidad. Igualmente, está consagrado en el art. 3 del Acuerdo Macro de las Naciones Unidas, en el Convenio de Diversidad Biológica que entró en vigencia en Colombia a partir de 1995, en el Convenio de Estocolmo y en el Protocolo de Cartagena (2000). del pp en la Convención de Diversidad Biológica pues a pesar de partir de una concepción antropocéntrica reconoce el valor intrínseco de la naturaleza sin requerir la existencia de daño que afecte de manera directa a la especie humana (Uprimmy Yepes y Orduz Salinas, 2012). A pesar de todo el marco jurídico, la ley y las interpretaciones sobre la aplicabilidad del principio han restringido su uso extenso determinando requisitos para su validez.

Volviendo al nivel interno, el Código de Recursos Naturales (Decreto 2811 de 1974) subrogado y derogado parcialmente por la Ley 99 de 1993, en el artículo 39 literal g, y en el artículo 193 estableció expresamente los elementos del pP en el ordenamiento colombiano (Santana, 2013). Sin embargo, solo hasta 1993 se consagró textualmente en la Ley 99, siguiendo los estándares internacionales que son caracterizados por la jurisprudencia como veremos más adelante. El numeral 6 del artículo 1 de dicha Ley establece que cuando exista (i) peligro de daño grave e irreversible, (ii) y pese a la falta de certeza absoluta haya un indicio con base en resultados de investigaciones científicas, no se debe postergar la adopción de medidas eficaces para impedir la degradación del medio ambiente. Adicionalmente, de esta definición se deriva el elemento (iii) de la inversión de la carga de la prueba, corresponde al interesado demostrar que la actividad económica restringida no genera dicho riesgo o deterioro corresponde al interesado demostrar que la actividad restringida no genera dicho riesgo o deterioro. 
La validez de la aplicación del Pp en Colombia está determinada por la confluencia de la serie de elementos enunciados anteriormente. Estos han sido ampliados a través de la jurisprudencia, por ejemplo, en la sentencia C-293 de 2002, la Corte Constitucional agregó calificativos a los componentes del Pp, de manera tal que para que su aplicación sea válida deben concurrir:

- Existencia del peligro de la ocurrencia de un daño al medio ambiente o a la salud.

- Que el daño sea irreversible.

- Que exista un mínimo de certeza sobre el peligro, es decir, que haya una probabilidad y no se base en meras especulaciones o riesgos hipotéticos.

- Que la decisión que la autoridad adopte se dirija a impedir la degradación del ambiente.

- Que la actuación se dé por medio de un acto motivado y excepcional.

- Que su aplicación obedezca a criterios de proporcionalidad.

De igual manera, su aplicación es restrictiva. Las limitaciones de la aplicación y alcance del pP son recogidos en la sentencia T-299 de 2008, en la cual la Corte se expresa así:

Frente a la primera inquietud, debe indicarse que decisiones tomadas en virtud del principio de precaución tienen siempre el carácter de provisionales, pues el enfoque de precaución no prevalece sobre la certeza científica; en tal sentido, su aplicación constituye un indicador de la necesidad de profundizar en las investigaciones, y no un límite a las mismas.

En relación con la segunda inquietud, es preciso señalar que la utilización del principio requiere la existencia de elementos científicos que indiquen la necesidad de intervención. No es la falta absoluta de información la base sobre la cual pueda aplicarse el principio de precaución, sino la valoración de indicios que indiquen la potencialidad de un daño. Los elementos que componen el presupuesto de aplicación del principio de precaución -daño potencial grave e irreversible, y un principio de certeza científica- son, en síntesis, criterios de razonabilidad para determinar la necesidad de intervención.

El principio de precaución, entonces, no necesariamente implica la intervención Estatal. Cuando los peligros potenciales son leves, o cuando el nivel de certeza científica es mínimo, o por completo inadecuado, la mejor decisión, puede ser no adoptar ninguna medida.

Por último, los costos derivados de la intervención, así como la interferencia en los derechos e intereses de otros grupos sociales, deben ser evaluados por el operador jurídico o administrativo que pretenda hacer uso del principio de precaución. En este sentido, la "adopción de medidas", debe inscribirse en el marco del principio de proporcionalidad. Es decir, las decisiones deben ser idóneas para la protección del medio ambiente y la salud; necesarias, en el sentido de que no se disponga de medidas que causen una menor interferencia; y los beneficios obtenidos de su aplicación deben superar los costos (constitucionales) de la intervención. (Negrillas fuera del texto original). 
Es pertinente señalar que algunas de las características introducidas por la jurisprudencia buscan corregir la percepción de arbitrariedad sobre el uso del principio en detrimento del interés particular. Al establecer estos requisitos se facilita la revisión objetiva y jurídica de su uso. Por ejemplo, el punto tercero (la justificación de la intervención estatal) hace referencia a un parámetro de necesidad sobre la aplicación: el principio de precaución obliga a las autoridades a evaluar si dicho riesgo es admisible o no, y con base en esa evaluación deben determinar el curso de acción (sentencia C-988 de 2004). Entonces, la necesidad de la aplicación del PP depende de la evaluación científica que identifica el riesgo potencial negativo sobre el medio ambiente o la salud; según sea un riesgo admisible o no, y el grado, se manifiesta la intervención del Estado.

Luego la regulación surge como una expresión de la conciencia de un riesgo que es moldeable según los avances técnicos en la materia. A manera de ejemplo, la sentencia C-988 de 2004 analiza si el sistema de registro de agroquímicos y pesticidas genéricos impone un nivel razonable de condiciones para realizar dicho proceso. En este fallo, la Corte avala la constitucionalidad de las condiciones concluyendo que la información científica aportada en lo relacionado con el expediente no permite desvirtuar la presunción de constitucionalidad de la opción legislativa en este campo, en la medida en que la regulación adoptada por las normas acusadas aparece compatible con el principio de precaución. La Corte no descarta que evidencias ulteriores muestren que ese procedimiento no sea suficiente o que en casos concretos surjan evidencias sobre los límites de este o de las licencias que con base en aquel se expidan; ello podrá hacer procedentes acciones judiciales o instancias y procedimientos administrativos en casos concretos.

\section{B. Casos de municipios emblemáticos del principio de precaución}

Una vez aclarado el concepto del pp continuamos con el orden propuesto inicialmente. Consideramos los casos estudiados como una manifestación del pP porque corresponden a la materialización de la obligación de los particulares y de las autoridades, respectivamente, de tomar medidas de protección frente a cualquier actividad de la cual haya prueba suficiente sobre la alta probabilidad de causar daños irremediables sobre el medio ambiente y la salud humana. Bajo este entendido, ¿por qué el rechazo de la minería está bajo los supuestos de aplicación del pp?

Primero, porque hay una relación entre el comportamiento humano y las amenazas a su entorno; las preocupaciones sociales que generaron los rechazos locales a la minería por problemas ambientales y de salubridad se explican por la relación de determinación social entre el ambiente y la salud, que es un proceso continuo definido por la geoecología. Esta última consiste en "la manera según la cual la transformación de las estructuras ecológicas revierten sus efectos en las condiciones de vida de los seres humanos" (Idarraga, 2012). 
Segundo, existe evidencia científica que hace cuestionable la actividad extractiva, ya que demuestra la alta probabilidad de causar daños graves e irreversibles sobre el ambiente y la salud humana a largo plazo. Si bien las consecuencias de la actividad no se identifican de manera absoluta, tal vez para no atribuirle una causa única erróneamente, las ya determinadas tienen un nivel de probabilidad muy alto, lo cual permite hablar de la aplicación del principio de precaución y no de prevención como se explicó en la sección precedente.

Las condiciones de vida de los seres humanos son seriamente alteradas con la presencia de la actividad minera. Pese a que, a nivel central, la Contraloría General de la República identifica una afectación marginal de las condiciones ambientales y de salubridad, hay ausencia de datos puntuales y sistemáticos sobre los problemas de salud en zonas de gran minería (Fierro, 2012). Este mismo autor explica que estudios locales revelan dichos impactos. Por ejemplo, la Secretaría de Ambiente de la Jagua, en 2007 informó que el ingreso de la mitad de los niños hospitalizados se debía a infección respiratoria aguda, cuyo origen es atribuible a la única actividad industrial de la zona: la minería. De igual manera, la contaminación provocada por el uso de mercurio, común en la minería legal e ilegal, también es un criterio de determinación social. Tanto los vertimientos y la contaminación de ríos como las emisiones al aire son un problema de tal magnitud que, en el caso de Segovia, en Antioquia, han sido declarados problema de salud pública y de seguridad alimentaria (Fierro, 2012). La contaminación de tierras y del agua afecta no solo la agricultura sino la vocación agrícola de algunas regiones.

Tercero, el daño al medio ambiente y la salud que origina la actividad extractiva es grave e irreversible. Proviene principalmente del uso del mercurio, metal que es emitido como vapor a la atmósfera por causas naturales y por la actividad humana, y es reincorporado a la tierra por el ciclo hidrológico que lo filtra en los suelos llegando a reservorios de agua subterráneos que a su vez están conectados con el mar. Esto produce una expansión de partículas de mercurio en la totalidad del sistema ecológico: en los sueIos, en el agua, en el aire, etc. (Gasca, 2000). La afectación de la salud se debe entonces a las toxinas liberadas y al consumo de alimentos cuya producción está afectada por la expansión del mercurio.

Cuarto, la decisión adoptada está claramente dirigida a impedir la degradación del ambiente. Finalmente, la actuación se da por medio de un acto motivado y excepcional, pues las decisiones pasan por un proceso de debate en el cual la motivación es ardua y continua en el proceso democrático que surten los entes colegiados territoriales. Según el artículo 73 de la Ley 136 de 1994, para que un proyecto sea Acuerdo requiere dos debates en distintos días, el primero en la comisión designada por la Secretaría del Concejo, y el segundo en sesión plenaria tres días después de haber sido aprobado en la comisión.

En este orden de ideas, los casos narrados de los municipios autoproclamados no mineros son una expresión de operatividad del pp surtida en 
dos etapas con distintos actores: la primera de movilización y de actuaciones de participación ciudadana, la segunda de formalización y toma de decisiones a través de instrumentos jurídicos como Acuerdos y Ordenanzas en las que se establece el Plan de Ordenamiento Territorial y se define el uso del suelo. Ambos actúan bajo el mandato de protección al medio ambiente instituido en los artículos 79 y 95 de la Constitución Política.

\section{La vulneración del principio de precaución}

Todo lo anterior demuestra que los acuerdos mediante los cuales se excluye la actividad minera de un territorio pueden ser explicados a la luz a la operatividad del pp. Ahora, ¿qué implicaciones tiene el artículo 2 del Decreto 0934 de 2013 sobre el PP?

Retomemos la norma citada. Esta dispone que a través del ordenamiento territorial no es posible hacer directa ni indirectamente el ordenamiento minero, salvo previa aprobación de las autoridades nacionales, y añade en el parágrafo 1 que “los Concejos Municipales y las Asambleas Departamentales no podrán establecer zonas del territorio que queden permanentemente o transitoriamente excluidas de la minería mediante acuerdos municipales $u$ ordenanzas departamentales respectivamente, por exceder el ámbito de sus competencias".

Entonces, la principal implicación de la norma estudiada en relación con el pp es que la elimina como una expresión autónoma y soberana. Ade- más, subordina su aplicación en materia minera a la autorización de entidades nacionales, y consecuentemente al reducir el uso de esta herramienta de amparo restringe la obligación de protección del medio ambiente por parte de particulares y de autoridades territoriales. Es decir, la obligación de protección del medio ambiente se mantiene siempre y cuando las medidas de protección no afecten la actividad minera, salvo autorización de entidades nacionales. Esta subordinación en materia de ordenamiento territorial también se ve reflejada en la afectación de la participación democrática, el ejercicio de la función pública y la formulación de políticas públicas como veremos en seguida.

\section{LIMITACIÓN DE PRINCIPIOS CONSTITUCIONALES DE DISEÑO INSTITUCIONAL}

En la expedición de acuerdos municipales que excluyen la minería a nivel territorial también confluyen la participación democrática, el ejercicio de la función pública y la formulación de políticas públicas. La primera permitiendo "la participación de todos en las decisiones que los afectan y en la vida económica, política y administrativa y cultural" (art. $2 \mathrm{cP}$ ), dado que se originó y fue impulsada por mecanismos de participación ciudadana y autodeterminación. Por otro lado, el ejercicio de la función pública se presentó bajo los principios que la rigen según el art. 209 de la cP, tales como el principio de descentralización y desconcentración. Finalmente, el caso de estudio también consiste en una expresión de política pública indirecta de 
prevención de riesgos ambientales y de salud, pues como ya se explicó anteriormente, a pesar de no estar expresa en las decisiones, estas emanan de preocupaciones de esta índole y son el origen de las movilizaciones sociales.

A continuación explicaremos la incidencia negativa de la prohibición contenida en el artículo 2 del Decreto 0934 de 2013 en la materialización de la participación democrática, el ejercicio de la función pública y la formulación de políticas públicas.

\section{A. La participación democrática}

La subordinación de la toma de decisiones se traduce en una limitación al ejercicio democrático de las Asambleas Departamentales y de los Concejos Municipales, y a los mecanismos de participación ciudadana que los activan o legitiman, en últimas, la voluntad del constituyente.

Si bien la naturaleza de los concejos y asambleas es eminentemente administrativa, las decisiones que adoptan cumplen con un papel democrático en cuanto su actividad se rige por los parámetros de la democracia representativa pues se integran y conforman a través del voto a nivel territorial-. Siendo elegidos sus miembros por voto popular, deben asegurar el pluralismo, la participación, el principio de las mayorías y la publicidad de sus actos, tal como ocurre con la actividad legislativa (sentencia C-008 de 2003). Recordemos que el carácter sustancial del procedimiento legislativo abarca momentos como la reunión, y actividades como la participación y la decisión. En su aspecto sustantivo cada una de las actuaciones sigue preceptos de la mayoría, el pluralismo político y la publicidad (sentencia C-141 de 2010, citada por la C-685 de 2011).

La restricción introducida por el Decreto 0934 de 2013 contradice estos mandatos constitucionales y la jurisprudencia de la Corte Constitucional. Ignora que el principio democrático es universal y expansivo (sentencia T-263 de 2010). ${ }^{5}$ Esta última característica se presume en una democracia participativa pues "se trata de una maximización progresiva de los mecanismos que permiten el acceso al poder político, y el ejercicio y control del mismo, así como la injerencia en la toma de decisiones" (subrayas añadidas) (Corte Constitucional. Sentencia C-179 de 2002). Por ello, la Corte ha sido enfática en cuanto al deber de los servidores públicos "de incentivarla y no torpedearla, ya que la inspección del pueblo en los asuntos, actuaciones e implementaciones políticas, como el incumplimiento del programa de gobierno, son fundamentales para la democratización social" (Corte Constitucional. Sentencia T-263 de 2010).

Ahora, para ilustrar la restricción a la participación ciudadana es suficiente referirse a dos

$5 \quad$ Cita la sentencia C-089 de 1994: "La breve relación anterior de las normas constitucionales sobre las que se edifica la democracia participativa, es suficiente para comprender que el principio democrático que la Carta prohíja es a la vez universal y expansivo. Se dice que es universal en la medida en que compromete variados escenarios, procesos y lugares tanto públicos como privados y también porque la noción de política que lo sustenta se nutre de todo lo que vitalmente pueda interesar a la persona, a la comunidad y al Estado y sea por tanto susceptible de afectar la distribución, control y asignación de poder social. El principio democrático es expansivo pues su dinámica lejos de ignorar el conflicto social lo encauza a partir del respeto y constante reivindicación de un mínimo de democracia política y social que, de conformidad con su ideario, ha de ampliarse progresivamente conquistando nuevos ámbitos y profundizando permanentemente su vigencia, lo que demanda por parte de los principales actores públicos y privados un denodado esfuerzo para su efectiva construcción". 
casos. En el municipio de Piedras la participación ciudadana se dio mediante una consulta popular, en la cual los habitantes debían expresar en las urnas si estaban o no de acuerdo con que se realizaran en este municipio tolimense "actividades de exploración, explotación, tratamiento, transformación, transporte o lavado de materiales, provenientes de las actividades de explotación minera aurífera a gran escala, almacenamiento y empleo de materiales nocivos para la salud y el medio ambiente". De las 5105 personas del censo del municipio acudió a las urnas el 58,90\%, es decir, 3007 votantes, de los cuales 2971 optaron por el "no" y solo 24 por el "sí", además de otros 12 votos nulos o no marcados (Portafolio, 2013). En el municipio de El Cerrito, en Santander, los habitantes impulsaron la prohibición de actividad minera o industrial que pudiera afectar la función esencial de abastecimiento de agua del páramo El Almorzadero, gracias a la recolección de 1051 firmas avaladas por la Registraduría General de la Nación. El 27 de agosto de 2010, con el voto unánime del Concejo, se aprobó dicha iniciativa, delimitando el territorio del páramo como zona de especial protección. Con el aval del alcalde, se benefició a 46000 habitantes del área de influencia del páramo y 6200 de El Cerrito (Sandoval, 2013).

En consecuencia, eliminar la facultad de entidades territoriales de debatir y decidir sobre temas mineros, dentro de un proceso democrático y en representación directa de sus electores, equivale a contrariar las principales normas constitucionales que enfatizan el valor fundante del principio democrático que busca garantizar la participación de manera permanente, en procesos que no necesariamente son electorales (Corte Constitucional. Sentencia C-008 de 2013). El preámbulo y los artículos 1, 2 y 40 de la cp coinciden en que a raíz del orden democrático y participativo se debe facilitar la participación de los ciudadanos y de su control político, y este es uno de los fines del Estado. De ello también deriva la contradicción del artículo 3 de la $\mathrm{CP}$, ya que menosprecia la soberanía popular que impulsó la prohibición minera territorial en algunos casos.

\section{B. La función pública}

La prohibición desconoce parámetros del ejercicio de la función pública en relación con los concejos y las autoridades ambientales territoriales. ${ }^{6}$ Por un lado, el principio de descentralización se realiza en el ejercicio de la competencia, atribuida por la ley orgánica a los concejos y ejercida bajo los principios de coordinación, concurrencia y subsidiariedad (art. 288 cP). La Corte Constitucional ha tenido por cierto que la “legislación orgánica territorial representa, dentro del marco de la unidad nacional, una protección de la autonomía territorial y de todo lo que ella significa; es pues una garantía institucional de la autonomía" (sentencia C-795 de 2000).

En efecto, los acuerdos municipales son un instrumento que concilia la idea de República

\footnotetext{
6 De acuerdo con el art. 209 de la cP, la función administrativa "se desarrolla con fundamento en los principios de igualdad, moralidad, eficacia, economía, celeridad, imparcialidad y publicidad, mediante la descentralización, la delegación y la desconcentración de funciones. Las autoridades administrativas deben coordinar sus actuaciones para el adecuado cumplimiento de los fines del Estado". También: artículo 3 de la Ley 489 de 1998 y art. 63 de la Ley 99 de1993).
} 
Unitaria con la de autonomía territorial, en temas como el ordenamiento del desarrollo del territorio, el uso del suelo y la preservación y defensa de su patrimonio cultural y ecológico, de conformidad con los artículos 311 y 313 de la Constitución Política. Igualmente, se opone a lo dispuesto en el art. 33 de la Ley 136 de 1994 y la Ley 388 de 1997, que otorgan a los concejos la competencia de determinar el uso del suelo e imponen su aprobación cuando el desarrollo de proyectos de naturaleza turística, minera o de otro tipo, amenace con crear un cambio significativo en el uso del suelo. La prohibición afecta estas competencias otorgadas a los concejos de manera fehaciente, puesto que en caso de tener cualquier impacto sobre la minería, sus decisiones serían nulas según el parágrafo 2 .

De la misma manera, al abstraer competencias asignadas a los concejos municipales y asambleas departamentales (art. 313 num. 7 y 9 $\mathrm{CP})$, la prohibición incurre en la misma conducta de vaciamiento de competencias que deriva en el desconocimiento del principio de descentralización, como ya lo ha estudiado la Corte Constitucional en la sentencia C-149 de 2010, donde se ocupó de la tensión que existe entre los principios unitario y autonómico a través del análisis de constitucionalidad del artículo 79 de la Ley 1151 de 2007, y encontró que al desconocer la participación activa de las entidades territoriales en la definición, formulación, adopción y ejecución de los macroproyectos de interés social nacional, se vacía la competencia territorial y permite al gobierno central imponer sus interpretaciones y actuaciones aún sobre el impacto local que pueda presentarse en un determinado caso. El estudio insiste en la previsión de la Carta de una protección especial a la competencia de estas entidades territoriales, puesto que es una garantía institucional para la autonomía de las entidades territoriales por virtud de la cual se fija en la materia un núcleo o reducto indisponible por parte del legislador. De la misma manera, la Corporación establece que debe haber un equilibrio entre los dos principios, de tal manera que se respete el ámbito de la autonomía descrito en la Constitución; así, el artículo 288 determina que las competencias atribuidas a los distintos niveles territoriales deberán ejercerse conforme a los principios de coordinación, concurrencia y subsidiariedad. La norma analizada, contrariamente, impone a las entidades territoriales una subordinación de las decisiones en materia minera, apartándose de estos principios.

Además, en materia de ordenamiento territorial, los concejos están sujetos a temas de su competencia y determinantes, que constituyen normas de superior jerarquía, de acuerdo con la Constitución y las leyes. Recordemos que los determinantes enumerados en el artículo 10 de la Ley 388 de 1997 son taxativos según la jurisprudencia del Consejo de Estado (sentencia del 18 de marzo de 2010).

Por su lado, la prohibición contenida en el artículo 2 del Decreto 0934 de 2013 se eleva a la misma categoría de determinante de las competencias de los entes territoriales en materia de ordenamiento y uso del suelo, y por consiguiente en lo referente a la actividad minera. Es decir, mediante la formulación relacionada con 
el "carácter de actividad de interés público de la minería", soportada por el art. 13 de la Ley 685 de 2001 que le atribuye esta calidad, pretende excusar el nuevo determinante de competencia. A nuestro parecer, el art. 10 de la Ley 388 de 1997 determina un marco inamovible del ámbito de competencia sustancial del ordenamiento territorial y por ello aplica a las decisiones emitidas por medio de los acuerdos municipales.

Por otro lado, las autoridades ambientales locales también son relevadas de sus competencias, quebrantando el principio de descentralización. Para la Corte Constitucional, "el ordenamiento territorial se constituye en una herramienta determinante para la planificación y uso del suelo, ya que, por su intermedio, se pretende garantizar el desarrollo sostenible de los recursos naturales procurando que exista un equilibrio entre la oferta y la demanda ambiental, en lo que se relaciona con la ejecución de los procesos de desarrollo municipal y distrital" (Sentencia C-431 de 2000). Por ello, el Plan de Ordenamiento Territorial (РОТ) exige para su adopción un estudio previo por parte de las autoridades ambientales, las Corporaciones Autónomas Regionales (CAR) y las Corporaciones de Desarrollo Sostenible (CDS), quienes actúan en cumplimiento de su obligación constitucional de proteger el medio ambiente, conforme a los artículos $5^{\circ}$ y $9^{\circ}$ de la Ley 388 de 1997. Estas conforman la estructura del Estado en calidad de entidades descentralizadas por servicios, lo que implica su experticia en los temas de protección al medio ambiente, sin dejar a su libre arbitrio su actividad. Los lineamientos jurisprudenciales sostienen que si bien es cierto: las corporaciones autónomas regionales y de desarrollo sostenible están sometidas a la ley y a las decisiones de la administración central en materia ambiental, pues el tema ecológico es del resorte de la autoridad nacional, no menos cierto es que esta previsión no puede llevarse al extremo de impedir que las CAR ejerzan con plenitud sus funciones ni supone en manera alguna una autorización para invadir la esfera local (Corte Constitucional. Sentencia C-598-10).

En este mismo orden de ideas, el principio de rigor subsidiario (art. 63 de la Ley 99 de 1993) que representa la descentralización en el derecho ambiental colombiano, en la cual se brinda mayor protección a la experiencia e inmediatez de la autoridad local respecto a la nacional, es vulnerado por la prohibición cuestionada. Este principio propone que las decisiones tomadas por las autoridades locales no pueden ser más permisivas que las nacionales cuando estas últimas son adecuadas para la protección integral del medio ambiente. ${ }^{7}$ No obstante, en el caso, sustraer la obligación de proteger el medio ambiente de la competencia de las CAR y las CDS es contrariar el principio en su integridad. En efecto, la norma estudiada releva a los municipios y las entidades ambientales, que tienen mayor conocimiento de los impactos negativos de la

"En este orden de ideas, del principio de rigor subsidiario se desprende que si la regulación o las medidas de superior jerarquía, con un ámbito de competencia territorial más amplio, son adecuadas y suficientes para la protección integral del medio ambiente y los recursos naturales renovables, las autoridades regionales o locales de inferior jerarquía no tendrían competencia para darle aplicación, por sustracción de materia. Por el contrario, si la regulación o las medidas de superior jerarquía no son adecuadas y suficientes, dichas autoridades sí tendrían competencia para aplicarlo, en ejercicio de su autonomía, por tratarse de la gestión de un interés propio, que desborda la competencia de las autoridades superiores" (sentencia C-554 de 2007). 
minería debido a la inmediatez fáctica, de la posibilidad de decidir, por lo que han actuado en aras de una mayor protección, dando prevalencia a las decisiones del nivel central.

Adicionalmente, la distribución de competencias está exclusivamente a cargo del legislador y su protección vislumbra la importancia de esta en varios niveles (art. 150 num. 4 сP). Esto quiere decir, además, que el mmE carecía de competencia para redistribuir la competencia de que trata el art. 2 del Decreto 394 de 2013. La distribución cuidadosa de competencias ingeniada por el legislador es una base primordial de la organización del Estado, y está íntimamente relacionada con:

la necesidad de preservar la diversidad de concepciones que las comunidades tienen en relación con el medio ambiente, lo que permite a las personas participar en las decisiones que las afectan de manera más directa e inminente. En esa medida, el constituyente previó un ámbito de protección medioambiental acorde con la división política del territorio y con la diversidad cultural colombianas, en el que asambleas, concejos y autoridades indígenas, cumplen un papel determinante (Corte Constitucional. Sentencia C-894 de 2003).

En conclusión, al subordinar a las entidades político-administrativas, cuyos miembros son elegidos popularmente, a la voluntad del gobierno y a las autoridades ambientales centrales, la prohibición desestabiliza la estructura del Estado y anula parámetros de coordinación entre el nivel central y el territorial, tal como el principio de rigor subsidiario y la prelación de la voluntad popular alineada a preceptos constitucionales, en materia minera.

\section{Política pública}

La prohibición cuestionada incide igualmente en la formulación de una política preventiva en materia ambiental y en la salud. El rol del ordenamiento territorial en la formulación de las políticas públicas ha evolucionado a raíz de las deficiencias de la racionalidad puramente económica en relación con el desarrollo, de la cual derivan diferencias en las condiciones y calidad de vida de la población, y consecuentemente la fragmentación de territorios nacionales y subregionales. Igualmente, la creciente influencia de fuerzas económicas y sociales extranjeras incide en el modelo de localización de actividades y de usos del suelo. Ambas condiciones otorgan importancia a las políticas de ordenamiento territorial para que se constituyan en un mecanismo de defensa de la soberanía, de los intereses locales y como mecanismo redistributivo y preventivo, mediante el rechazo de actividades que acentúen dichas diferencias, como es el caso de la minería.

Esta línea de pensamiento es planteada por el investigador de la Comisión Económica para América Latina y el Caribe (CEPAL), Pedro Montes Lira (2001), quien sostiene que “(h)oy [las políticas territoriales] son un instrumento o mecanismo económicamente racional para enfrentar los problemas y desafíos de sociedades donde cada vez se hace más complejo el producir, distribuir y consumir bienes y servicios. A su vez, cobijan problemas de enorme magnitud." Además, 
deberían propender a un desarrollo integrado, armonioso y equitativo, preservando y mejorando las condiciones ambientales, e incluyendo aspectos sociales, económicos y ambientales, e integrar y acoger la diversidad y complejidad ambiental.

La prohibición del Decreto 0934 de 2013 impide la realización de lo descrito. En lugar de dar espacio a las preocupaciones sociales puestas de manifiesto en el proceso de socialización de las iniciativas populares, en los debates de los acuerdos y en algunos casos en los referendos, se da prelación al interés de la inversión extranjera que incide en las prioridades del gobierno central y en entidades como el MME, quien define cuáles son los proyectos de interés nacional. Estas declaratorias, sujetas a los criterios establecidos por la Resolución 0341 de 2013 de la Agencia Nacional de Minería (ANM) favorecen a multinacionales como AngloAshanti, Carbones del Cerrejón LLC, Cerromatoso, Drummond Ltda., Carbones de la Jagua, Consorcio Minero Unido S. A. (ANM. Resolución 0592 de 2013). ${ }^{8}$

Este paralelismo entre los intereses nacionales y los de las multinacionales ha sido objeto de críticas, pues se asocia a las demás prerrogativas dadas al sector, que lo benefician de manera excesiva. El Centro de Investigaciones y Educación Popular (Cinep, 2012) identifica algunos

8 A nuestro parecer, es inconveniente que la ANm haya determinado los parámetros bajo los cuales los proyectos mineros fueron declarados como de interés nacional en la Resolución 0341 de 2013, pese a que el carácter de interés social lo estableció el legislador en el art. 13 del Código de Minas (Ley 635 de 2001). De cualquier manera, la utilidad o interés social de la actividad minera, como fundamento del Decreto, está en vilo ya que esta disposición fue demandada ante la Corte Constitucional en agosto de 2013 (Radicado D-9829). cambios favorables en la última década a favor de la inversión en el sector: 1) la flexibilización de procedimientos específicos para acceder a titulación y las condiciones de los agentes privados para el ejercicio de la actividad minera, 2) la reestructuración de los modelos de contratación tanto en minería (Ley 685 de 2001) como en hidrocarburos (Decreto 1760 de 2003), bajos los cuales la nación no participa en la explotación de sus minerales de manera directa, 3) la limitación a la nación con un rol de promotora y fiscalizadora de la minería, manteniendo la restricción a empresas mineras de capital público o mixto mediante la Ley 685 de 2001, y 4) la facilidad a la inversión privada dando prelación en el otorgamiento del título minero a quien primero lo solicite.

Por su parte, la Contraloría General de la Nación (2013), en una investigación extensa sobre la materia, dirigida por Luis Jorge Garay Salamanca, recalcó a manera de conclusión:

La declaratoria de utilidad pública e interés social de la industria minera (artículo $13 \mathrm{del}$ Código de Minas), está ocasionando una serie de conflictos a muchas regiones del país, por cuanto diversas entidades estatales están privilegiando dichas actividades sobre los derechos fundamentales de las comunidades y, por lo tanto, desconociendo la jerarquía de derechos previstos en el ordenamiento jurídico, lo que está conllevando procesos de desplazamiento de comunidades, que se ven obligadas a vender sus propiedades o ser expropiadas, sin que existan planes, programas, proyectos o mecanismos adecuados para evitar o, al menos, minimi- 
zar o compensar la pérdida a la que están sometidas (p. 52 ).

En efecto, la vulneración de derechos humanos de manera sistemática, derivada de la implantación de megaproyectos extractivos, es una realidad que ha sido documentada a manera de denuncia, a causa de la magnitud de la violencia ocasionada. La historia da fe de la violencia generada en el marco de la minería, por actores institucionales y actores armados al margen de la ley; las investigaciones del Cinep (2012) confirman que "en muchas regiones existe correlación con la violencia, extorsiones, asesinatos donde se han multiplicado las explotaciones que de manera creciente están controladas o pagan "peaje" a los grupos armados de todo tipo, desde las farc y el eLn hasta las llamadas "bacrim"” (p. 15). En el informe del Centro Internacional de Toledo para la Paz (CITpax Colombia) y el Observatorio Internacional DDR-Ley de Justicia y Paz (2012), sobre los actores armados en Colombia y la actividad extractiva, se advierte que

no es sorprendente que el mapa de las actividades extractivas en el país coincida con la ubicación de los grupos armados ilegales y que la minería ilegal haya contribuido al desarrollo de mercados de violencia. Las FARC son el grupo armado ilegal que más influencia ejerce en este sector, con presencia en departamentos como Antioquia, Bolívar, Caquetá, Casanare, Cauca, Chocó, Nariño y Tolima. Según la Policía, esa guerrilla obtendría hoy en día hasta $20 \%$ de sus recursos de la explotación ilegal de oro. Le sigue el ELN, con presencia en el Sur de Bolívar, Chocó, Nariño y Santander, seguido muy de cerca por las Ilamadas bandas criminales (BA-
CRIM), que están cada vez más involucradas en estas actividades principalmente en Antioquia, Sur de Córdoba, Cauca, Valle y Nariño (p. 7).

En el informe se describen, adicionalmente, los distintos modus operandi de estos grupos: extracción directa, utilización de empresas fachada, extorsión de productores y hurtos, entre otros.

Lo anterior permite dimensionar la actividad minera y la importancia de la prohibición local de esta en el contexto social y político colombiano. Las luchas sociales ya no son puntuales, pretendiendo la simple reivindicación de derechos laborales, ambientales y culturales, se trata de un rechazo sistemático del modelo minero, legitimado en la multiplicidad de actores presentes en las luchas y protestas en las que participa población rural afectada de manera directa, trabajadores independientes y asalariados urbanos. En este sentido, la prohibición a las entidades territoriales no permite una formulación de política pública integral de rechazo a las externalidades negativas, ya documentadas, de la actividad extractiva.

\section{CONCLUSIONES}

En nuestro concepto, la prohibición contenida en el artículo 2, parágrafos 1 y 2 del Decreto 0934 de 2013 del MmE constituye una limitación ilegítima del principio de precaución en materia minera y a la realización del principio de precaución, el principio democrático, el principio de descentralización de decisiones administrativas y ambientales, así como a la formulación de po- 
líticas preventivas en salud y medio ambiente. La prohibición injiere indebidamente al acotar los preceptos principales de cada uno de estos principios y al ser expedida por el MME, que se abroga una competencia otorgada exclusivamente al legislador.

La Ley 635 de 2001, cuyo artículo 13 atribuye la calidad de interés público a la actividad minera; el Decreto 0341 de 2013, que establece los criterios para calificar un proyecto minero como de interés nacional; y el Decreto 0934 de 2013 revelan el afán político de atraer inversión extranjera vía la industria minera, respondiendo a los intereses de los mayores inversionistas en el sector: las multinacionales propietarias de los proyectos amenazados por las prohibiciones municipales examinadas. De hecho, la estructura del artículo 2 del Decreto 0934 de 2013 revela que pese a estar formulada de manera general, está dirigida a "corregir" los casos concretos de municipios que se autodeclararon no mineros. La politización de la norma es tan evidente que su misma estructura la ilustra fielmente: dedica el parágrafo 2 a dilucidar cualquier duda sobre la nulidad de dichas decisiones por exceder la competencia de las entidades territoriales. En efecto, esta posición fue acogida para anular los acuerdos municipales de Jardín, ${ }^{9}$ Urrao, ${ }^{10}$ Caice-

9 Sentencia del Tribunal Administrativo de Antioquia, del 19 de abril de 2013, Sala Segunda de Oralidad, M. P.: Beatriz Elena Jaramillo Muñoz, que anula el Acuerdo Municipal n. 009 de 2012 del Concejo Municipal de Jardín, por haber excedido el Concejo Municipal su competencia al pretender excluir la minería de su territorio.

10 Sentencia del Tribunal Administrativo de Antioquia, del 10 de mayo de 2013, Sala Primera de Oralidad, M. P.: Yolanda Obando Montes, que anula el Acuerdo Municipal n. ${ }^{\circ} 020$ de 2012 del Concejo Municipal de Urrao, por haber excedido el Concejo Municipal su competencia al pretender excluir la minería de su territorio. do $^{11}$ y Cañasgordas ${ }^{12}$ por parte del Tribunal Administrativo de Antioquia, y estudiada en el caso del municipio de Piedras. Este último es conocido por la amenaza que representa la mina La Colosa, con gran potencial de explotación a nivel regional.

Finalmente, es posible afirmar que los intereses del sector minero se han institucionalizado y sobrepuesto sobre los intereses sociales:

Diversos estudios constatan que los excedentes de la minería y el petróleo no provocan mejoras significativas en las condiciones de vida de la población: la red de mercados es débil, la producción interna no es suficiente para abastecer los territorios donde se ubican las explotaciones minero-energéticas, las vías internas son deficientes y las troncales que las atraviesan no dan origen a procesos endógenos de desarrollo, y (e)I desarrollo minero actualiza los históricos problemas agrarios de la tierra y del desarrollo rural que no se han resuelto en el país (Cinep, 2012, p. 4).

Lo anterior, representado por la prohibición del art. 2 del Decreto 0934 de 2013, ha derivado en la desestabilización del equilibrio institucional entre el nivel nacional y el territorial, concentrando la competencia a nivel central. Es de

11 Sentencia del Tribunal Administrativo de Antioquia, del 30 de mayo de 2013, Sala Primera de Oralidad, M. P.: Yolanda Obando Montes, que anula el Acuerdo Municipal n. ${ }^{\circ} 003$ de 2013 del Concejo Municipal de Caicedo, por haber excedido el Concejo Municipal su competencia al pretender excluir la minería de su territorio.

12 Sentencia del Tribunal Administrativo de Antioquia, del 24 de julio de 2013, Sala Primera de Oralidad, M. P.: Álvaro Cruz Riaño S., que anula el Acuerdo Municipal n. ${ }^{\circ} 024$ de 2012 del Concejo Municipal de Cañasgordas, por haber excedido el Concejo Municipal su competencia al pretender excluir la minería de su territorio; advierte expresamente sobre la "extralimitación de funciones" de los miembros del Concejo. 
suma importancia recalcar que las afectaciones constitucionales que derivan de la prohibición analizada se concretizan en principios, cuyo orden superior en el ordenamiento jurídico exige un control arduo al respecto.

La persistencia de impulsar la locomotora minero-energética no parece encontrar otra explicación que la cooptación del Estado, reflejando las nuevas dinámicas del poder en el contexto de la globalización, que replantean el rol de este reduciéndolo a un intermediario del actor privado. Al mismo tiempo, la protesta contra la actividad minera en el contexto social y político colombiano dejó de ser una reivindicación individual aislada de derechos laborales, ambientales y culturales, para pasar a un rechazo sistemático en contra del modelo minero, que revela la disonancia entre lo local y lo nacional.

Para finalizar, es preciso hacer referencia al fallo de constitucionalidad que profirió la Corte Constitucional sobre el art. 37 de la Ley 685 de 2001, que sirve de fundamento al Decreto 0934 de 2013. Pese a que al momento solo se conoce el sentido del fallo, en el comunicado de prensa fechado el 5 de marzo de 2014 el cuerpo colegiado aboca la exequibilidad condicionada de la norma demandada. Esta última prohíbe que a través del Plan de Ordenamiento Territorial se excluya territorio de la actividad minera temporal o permanentemente. El fallo sujeta la armonía constitucional de la norma a la siguiente observancia:

siempre y cuando en el proceso de autorización para la realización de actividades de explora- ción y explotación minera -cualquiera sea el nombre que se dé al procedimiento para expedir dicha autorización por parte del Estado-se tengan en cuenta los aspectos de coordinación y concurrencia, los cuales se fundan en el principio constitucional de autonomía territorial. En este sentido, una autorización al respecto deberá dar la oportunidad a las entidades municipales o distritales involucradas de participar activa y eficazmente en dicho proceso, mediante acuerdos sobre la protección de cuencas hídricas y la salubridad de la población, así como del desarrollo económico, social y cultural de sus comunidades.

De la determinación citada resta analizar sus efectos respecto a la validez de las decisiones territoriales que utilizaron el Plan de Ordenamiento Territorial para excluir la minería de su jurisdicción, como es el caso del Distrito de Bogotá. Adicionalmente, queda en suspenso hasta la publicación de la sentencia en su texto integral, el alcance de la decisión de acuerdo con la amplitud que se le haya otorgado a la expresión "Plan de Ordenamiento Territorial", pues si bien se puede entender únicamente como el instrumento del mismo nombre, también puede ser interpretado como el conjunto de instrumentos que permiten ordenar el uso del suelo. En este último supuesto, la decisión de la Corte Constitucional abarcaría lo dispuesto en el Decreto 0934 de 2013, y el Consejo de Estado vería circunscrita su decisión respecto a la acción de nulidad que está en curso en contra del mismo ante la Sala de lo Contencioso Administrativo, Sección Tercera, con el número de radicado 11001032400020130032600. 


\section{Referencias}

ABColombia. (2012). Regalándolo todo: Ias consecuencias de una política minera no sostenible en Colombia. Londres: ABColombia.

Acción de inconstitucionalidad interpuesta ante la Corte Constitucional por Zulma Tatiana Blanco Buitrago en contra de artículo 37 de la Ley 685 de 2001 y el parágrafo 1 del artículo 2 del Decreto 0934 del 9 de mayo de 2013 por cuanto contradice la Constitución. Radicado D 9700.

Acción de inconstitucionalidad interpuesta ante la Corte Constitucional por Julio César Ardila Rojas en contra del artículo 2 y sus parágrafos 1 y 2 y el artículo 3 del Decreto 934 del 9 de mayo de 2013, por considerar que su expedición vulneró los mandatos de la Constitución Política de Colombia en sus artículos 313 , numerales 2,7 y 9, y el artículo 311 y 288. Radicado D 9821.

Acción de nulidad por inconstitucionalidad interpuesta por Bogotá Distrito Capital-Secretaría Ambiental en contra del Decreto 934 de 2013, ante la Sección Primera del Consejo de Estado, y presentada el 26 de junio de 2013.

Acuerdo $n^{\circ} .026$ de 2007. [Concejo Municipal de Coello (Tolima)]. "Por medio del cual se prohíben las actividades mineras en varias de las áreas en la cuenca del río Coello".

Acuerdo n. ${ }^{\circ} 009$ de 2012. [Concejo Municipal de Támesis (Antioquia)]. Por el cual se crea la protección especial del territorio en Támesis y se prohíben algunas prácticas.

Acuerdo n. ${ }^{\circ} 009$ del 2012. [Concejo Municipal de Jardín (Antioquia)]. Por medio del cual se excluye la actividad minera de la zona.

Acuerdo n. ${ }^{\circ} 020$ de 2012. [Concejo Municipal de Urrao (Antioquia)]. Por medio del cual se crea la protección del territorio en Urrao Antioquia y se prohíben algunas prácticas.

Acuerdo $n^{\circ} .31$ de 2012. [Concejo Municipal de Unión (Nariño)]. "Por el cual se crea la protección especial del territorio en el municipio de la Unión - Nariño y se prohíben algunas prácticas".

Acuerdo n. ${ }^{\circ} 003$ de 2013. [Concejo Municipal de Caicedo (Antioquia)]. Por medio del cual se crea la protección especial del Territorio de Caicedo y se prohíben algunas prácticas.

Centro de Investigación y Educación Popular -Cinep. (Octubre, 2012). Informe especial minería, conflictos sociales y violación de derechos humanos en Colombia. Segundo Informe. Bogotá D. C: Cinep Programa por la Paz.

Centro Internacional de Toledo para la Paz (CITpax Colombia) y Observatorio Internacional DDR- Ley de Justicia y Paz. (2012). Actores armados ilegales y sector extractivo en CoIombia. V Informe 2012. Bogotá D. C: Autores.

Conciudadanía. (2013). Somos muy timoratos y muy cobardes cuando se trata de defender lo público, y en el caso de la actividad minera, 
lo público es lo ambiental. Recuperado el 22 de octubre de 2013, de: http://conciudadania. org/2012/10/\%E2\%80\%9Csomos-muy-timoratos-ymuy-cobardes-cuando-se-trata-de-defender-lo-publico-y-en-este-caso-de-la-actividad-minera-lo-publico-es-lo-ambiental\%E2\%80\%9D/

Consejo de Estado. Sala de lo Contencioso Administrativo. Sección Primera. Sentencia de marzo 18 de 2010. Radicación número: 11001-03-24-000-2005-00185-01. Consejero ponente: Rafael E. Ostau de Lafont Pianeta.

Contraloría General de la República. (2013). Minería en Colombia: fundamentos para superar el modelo extractivista. Bogotá D. C: Contraloría.

Corte Constitucional. Comunicado de prensa n. ${ }^{\circ} 7$, del 5 de marzo de 2014. Referente al expediente D-9700. Sentencia C-123/14. M. P.: Alberto Rojas Ríos.

Corte Constitucional. Sentencia C-008 de 2003. M. P.: Rodrigo Escobar Gil.

Corte Constitucional. Sentencia C-089 de 1992. M. P.: Eduardo Cifuentes Muñoz

Corte Constitucional. Sentencia C-149 de 2010. M. P.: Jorge I. Palacio Palacios.

Corte Constitucional. Sentencia C-179 de 2002. M. P.: Marco G. Monroy Cabra.

Corte Constitucional. Sentencia C-293 de 2002. M. P.: Alfredo Beltrán Sierra.
Corte Constitucional. Sentencia C-431 de 2000. M. P.: Vladimiro Naranjo Mesa.

Corte Constitucional. Sentencia C-519 de 1994. M. P.: Vladimiro Naranjo Mesa.

Corte Constitucional. Sentencia C-528 de 1994.

M. P.: Fabio Morón Díaz.

Corte Constitucional. Sentencia C-554 de 2007.

M. P.: Jaime Araújo Rentería.

Corte Constitucional. Sentencia C-595 de 2010.

M. P.: Jorge Palacios Palacios.

Corte Constitucional. Sentencia C-598 de 2010. M. P.: Mauricio González Cuervo.

Corte Constitucional. Sentencia C-671 de 2001. M. P.: Jaime Araújo Rentería.

Corte Constitucional. Sentencia C-685 de 2011. M. P.: Humberto Sierra Porto.

Corte Constitucional. Sentencia C-795 de 2000. M. P.: Eduardo Cifuentes Muñoz.

Corte Constitucional. Sentencia C-894 de 2003. M. P.: Rodrigo Escobar Gil.

Corte Constitucional. Sentencia C-988 de 2004. M. P.: Humberto Sierra Porto.

Corte Constitucional. Sentencia T-263 de 2010. M. P.: Juan Carlos Henao Pérez.

Corte Constitucional. Sentencia T-411 de 1992. M. P.: Alejandro Martínez Caballero. 
Decreto 2119 de 1992. [Ministerio de Minas y Energía]. "Por el cual se reestructura el Ministerio de Minas y Energía, el Instituto de Asuntos Nucleares, IAN y Minerales de Colombia S. A., Mineralco". Diario Oficial, n. ${ }^{\circ}$ 40.704. Diciembre 31 de 1992.

Decreto 4134 de 2011. [Ministerio de Minas y Energía]. "Por el cual se crea la Agencia Nacional de Minería, ANM, se determina su objetivo y estructura orgánica". Diario Oficial, n. ${ }^{\circ}$ 48.242. Noviembre 3 de 2011.

Decreto 0381 de 2012. [Ministerio de Minas y Energía]. "Por el cual se modifica la estructura del Ministerio de Minas y Energía". Diario Oficial, n. ${ }^{\circ} 48345$. Febrero 16 de 2012.

Decreto 0934 de 2013. [Ministerio de Minas y Energía]. "Por el cual se reglamenta el artículo 37 de la Ley 685 de 2001". Diario Oficial, n. ${ }^{\circ}$ 48785. Mayo 9 de 2013.

Decreto 364 de 2013. [Alcaldía Mayor de Bogotá]. "Por el cual se adopta la modificación excepcional de las normas urbanísticas del Plan de Ordenamiento Territorial para Bogotá, y por medio del cual se compilan las disposiciones contenidas en los decretos distritales 619 de 2000, 469 de 2003 y 10 de 2004".

Decreto 705 de 2013. [Ministerio de Ambiente y Desarrollo Sostenible]. "Por medio de la cual se establecen unas reservas de recursos naturales de manera temporal como zonas de protección y desarrollo de los recursos naturales renovables o del ambiente y se dic- tan otras disposiciones". Diario Oficial, n. ${ }^{\circ}$ 48.854. Julio 17 de 2013.

Departamento Nacional de Planeación. (17 de marzo de 2014). Convenios internacionales sobre el medio ambiente suscritos por Colombia. Obtenido de: https://www.dnp.gov.co/ Programas/Ambiente/MedioAmbiente/Conveniosinternacionalessobremedioambientesus.aspx

Dirección de Minería Empresarial. (2013). Análisis del comportamiento del PIB minero en el primer trimestre de 2013. Bogotá D. C: Ministerio de Minas y Energía.

Fierro Morales, J. (2012). Políticas mineras en Colombia. Bogotá D. C.: Instituto Latinoamericano para una Sociedad y un Derecho alternativo (ILSA).

Flórez, M. (2013). En defensa del páramo de Santurbán. Cronología de una lucha que apenas comienza. En Universidad Nacional de Colombia, Plataforma Colombiana de Derechos Humanos, Democracia y Desarrollo y CEnsat Agua Viva, Minería, territorio y conflicto en Colombia (págs. 465-484). Bogotá D. C.: Universidad Nacional de Colombia.

García Parra, R. (2012). La Colosa, primer proyecto de minería a cielo abierto de lixiviación con cianuro en el centro de Colombia. Una letura alternativa desde el movimiento social y ambiental. En Universidad Nacional de CoIombia, Plataforma Colombiana de Derechos Humanos, Democracia y Desarrollo (PCDHDD) y 
CENSAT Agua Viva, Minería, territorio y conflicto en Colombia. Bogotá: AAv.

Gasca Álvarez, M. del P. (2000). Environmental Exposure to Mercury in Gold Mining: Health Impact Assessment in Guainía, Colombia. Revista Salud Pública, II(3), 233-250.

Idarraga Franco, A. (2012). El devenir de la minería transnacional en Colombia: incertidumbres en torno a la relación ambiente, trabajo y salud. En Universidad Nacional de Colombia, Plataforma Colombiana de Derechos Humanos, Democracia y Desarrollo y censat Agua Viva, Minería, territorio y conflicto en Colombia (págs. 97-108.). Bogotá D. C.: Universidad Nacional de Colombia.

Indepaz. (2012). Minería: ¿del extractivismo a una nueva era? Bogotá: Internacional Alert.

Ley 99 de 1993. "Por la cual se crea el Ministerio del Medio Ambiente, se reordena el Sector Público encargado de la gestión y conservación del medio ambiente y los recursos naturales renovables, se organiza el Sistema Nacional Ambiental, sINA y se dictan otras disposiciones". Diario Oficial, n. ${ }^{\circ} 41.146$.

Ley 136 de 1994. “Por la cual se dictan normas tendientes a modernizar la organización y el funcionamiento de los municipios". Diario Oficial, n. ${ }^{\circ} 41.377$.

Ley 143 de 1994. "Por la cual se establece el régimen para la generación, interconexión, transmisión, distribución y comercialización de electricidad en el territorio nacional, se conceden unas autorizaciones y se dictan otras disposiciones en materia energética". Diario Oficial, n. ${ }^{\circ} 41.434$, de 12 de julio de 1994.

Ley 388 de 1997. "Por la cual se modifica la Ley $9^{a}$ de 1989, y la Ley $3^{a}$ de 1991 y se dic$\tan$ otras disposiciones". Diario Oficial, n. ${ }^{\circ}$ 43.091 y septiembre 12 de 1997. Diario Oficial, n. ${ }^{\circ} 43.127$.

Ley 1151 de 2007. "Por la cual se expide el Plan Nacional de Desarrollo 2006-2010". Diario Oficial, n. ${ }^{\circ} 46.700$.

Ley 685 de 2010. "Por la cual se expide el Código de Minas y se dictan otras disposiciones". Diario Oficial, n. ${ }^{\circ} 44.545$, de 8 de septiembre de 2001.

Ley 1450 de 2011. "Por medio de la cual se expide el Plan Nacional de Desarrollo, 20102014". Diario Oficial, n. ${ }^{\circ} 48.102$, de 16 de junio de 2011.

Ministerio del Medio Ambiente, Departamento Nacional de Planeación, Instituto Alexander von Humboldt. (s. f.). Política Nacional de biodiversidad. Bogotá, D. C.: Autores.

Montes Lira, P. F. (Diciembre, 2001). El ordenamiento territorial como opción de políticas urbanas y regionales en América Latina y el Caribe. Serie Medio Ambiente y Desarrollo, 45. Santiago de Chile: Cepal, División de Medio Ambiente y Asentamientos Humanos. 
Osorio, C. (14 de octubre de 2010). El legado minero de Uribe. Recuperado el 16 de enero de 2013, de: http://lasillavacia.com/historia/18648

PBI Colombia. (2011). Minería en Colombia: ¿A qué precio? Boletín informativo (18).

Portafolio. (29 de julio de 2013). El municipio de Piedras rechazó la minería en su territorio. Recuperado el 16 de marzo de 2014, de Portafolio.co: http://www.portafolio.co/economia/ piedras-rechazo-minero-referendum

Redacción Tolima. (2013). Multitudinaria marcha contra la gran minería en Tolima. Recuperado el 15 de marzo, de eltiempo.com: http:// www.eltiempo.com/colombia/tolima/ARTICULO-WEBNEW NOTA INTERIOR-12848584.html

Resolución 1518 de 2012. [Agencia Nacional de Minería]. "Por la cual se suspenden los trámites de sustracción de la Reserva Forestal de la Amazonia declarada por el artículo $1^{\circ}$ literal g) de la Ley $2^{a}$ de 1959 para actividades mineras con base en el principio de precaución". Diario Oficial, n. ${ }^{\circ} 48555$, el 16 de septiembre de 2012.

Resolución 0045 de 2012. [Agencia Nacional de Minería]. "Por medio de la cual se declaran y delimitan unas Zonas Estratégicas Mineras y se toman otras determinaciones". Diario Oficial, n. ${ }^{\circ}$ 48.483, 6 de julio de 2012.

Resolución 0341 de 2013. [Agencia Nacional de Minería, Vicepresidencia de Seguimiento, Control y Seguridad Minera]. "Por medio de la cual se designan algunos proyectos como de interés nacional". A la fecha no ha sido publicada en el Diario Oficial de Colombia.

Resolución 0592 de 2013. [Agencia Nacional de Minería - Vicepresidencia de Seguimiento, Control y Seguridad Minera]. "Por medio de la cual se designan algunos proyectos como de interés nacional". A la fecha no ha sido publicada en el Diario Oficial de Colombia.

Reyes Beltrán, P. I. y León, I. P. (2013). Las nuevas "guerras justas" y la política (neo) extractivista global: nuevos escenarios de biopoder. En Universidad Nacional de Colombia, Plataforma Colombiana de Derechos Humanos, Democracia y Desarrollo y CENSAT Agua Viva, Minería, territorio y conflicto en Colombia (págs. 109-136). Bogotá, D. C.: Universidad Nacional de Colombia.

Roa Avendaño, T. (2013). Palabras para narrar la resistencia. Las luchas por el agua y el territorio. En Universidad Nacional de Colombia, Plataforma Colombiana de Derechos Humanos, Democracia y Desarrollo y censat Agua Viva. Minería, territorio y conflicto en Colombia (págs. 399-412). Bogotá, D. C.: Universidad Nacional de Colombia.

Sandoval, S. (2013). La resistencia a la minería en el páramo El Almorzadero. En Universidad Nacional de Colombia, Plataforma Colombiana de Derechos Humanos, Democracia y Desarrollo y CENSAT Agua Viva, Minería, territorio y conflicto en Colombia (págs. 413-426). Bogotá, D. C.: Universidad Nacional de Colombia. 
Santana, P. (2013). Las controversias en el derecho internacional ambiental y los retos en la aplicación del principio de precaución en el ámbito local. Revista de Derecho Público (30), 1-54.

Soto, M. V. (1996-1997). Principios generales del derecho ambiental internacional. Journal of International and Comparative Law, 416431.

Toro Peréz, C., Fierro Morales, J., Coronado Delgado, S., Roa Avendaño, T. (2012). Minería, territorio y conflicto en Colombia. Bogotá: Universidad Nacional de Colombia.

Tribunal Administrativo de Antioquia. Sentencia del 10 de mayo de 2013, Sala Primera de Oralidad, M. P.: Yolanda Obando Montes, que anula el Acuerdo Municipal n. ${ }^{\circ} 020$ de 2012 del Concejo Municipal de Urrao, por haber excedido el Concejo Municipal su competencia al pretender excluir la minería de su territorio.

Tribunal Administrativo de Antioquia. Sentencia del 19 de abril de 2013, Sala Segunda de Oralidad, M. P.: Beatriz Elena Jaramillo Muñoz, que anula el Acuerdo Municipal n. ${ }^{\circ} 009$ de 2012 del Concejo Municipal de Jardín, por haber excedido el Concejo Municipal su competencia al pretender excluir la minería de su territorio.

Tribunal Administrativo de Antioquia. Sentencia del 24 de julio de 2013, Sala Primera de Oralidad, M. P.: Álvaro Cruz Riaño S., que anula el Acuerdo Municipal n. ${ }^{\circ} 024$ de 2012 del Concejo Municipal de Cañasgordas, por haber excedido el Concejo Municipal su competencia al pretender excluir la minería de su territorio y advierte expresamente sobre la "extralimitación de funciones" de los miembros del Concejo".

Tribunal Administrativo de Antioquia. Sentencia del 30 de mayo de 2013, Sala Primera de Oralidad, M. P.: Yolanda Obando Montes, que anula el Acuerdo Municipal n. 003 de 2013 del Concejo Municipal de Caicedo, por haber excedido el Concejo Municipal su competencia al pretender excluir la minería de su territorio.

Uprimmy Yepes, R. y Orduz Salinas, N. (2012). El principio de precaución y la Amazonía. Documento de Consultoría para el Proyecto Amazonía Posible y Sostenible. Bogotá: CIJUS. 